\title{
Photocatalytic overall water splitting under visible light enabled by a par- ticulate conjugated polymer loaded with iridium
}

\author{
Yang Bai, ${ }^{1,2}$ Chao Li, ${ }^{3}$ Lunjie Liu, ${ }^{1}$ Yuichi Yamaguchi, ${ }^{4}$ Bahri Mounib, ${ }^{5}$ Haofan Yang ${ }^{1}$, Adrian Gardner, ${ }^{3}$ \\ Martijn A. Zwijnenburg, ${ }^{6}$ Nigel D. Browning, ${ }^{5}$ Alexander J. Cowan, ${ }^{3,{ }^{*}}$ Akihiko Kudo, ${ }^{4, *}$ Andrew I. Cooper ${ }^{1, *}$ \\ and Reiner Sebastian Sprick, $1,7, *$ \\ ${ }^{1}$ Materials Innovation Factory \& Department of Chemistry, University of Liverpool, 51 Oxford Street, \\ Liverpool L7 3NY, UK. \\ ${ }^{2}$ Institute of Materials Research and Engineering, Agency for Science Technology and Research, \#08- \\ 03, 2 Fusionopolis Way, Innovis, Singapore, 138634, Singapore. \\ ${ }^{3}$ Stephenson Institute for Renewable Energy, University of Liverpool, Peach Street, Liverpool L69 7ZF, \\ UK. \\ ${ }^{4}$ Tokyo University of Science, Department of Applied Chemistry, 1-3 Kagurazaka, Shinjuku-ku, Tokyo, \\ Japan \\ ${ }^{5}$ Albert Crewe Centre for Electron Microscopy, University of Liverpool, Liverpool L69 3GL, UK. \\ ${ }^{6}$ Department of Chemistry, University College London, 20 Gordon Street, London WC1H 0AJ, UK. \\ ${ }^{7}$ Department of Pure and Applied Chemistry, University of Strathclyde, Thomas Graham Building, \\ 295 Cathedral Street, Glasgow G1 1XL, UK.
}

\begin{abstract}
The production of hydrogen from water via solar water splitting is a potential method to overcome the intermittency of the Sun's energy by storing it as a chemical fuel. Inorganic semiconductors have been studied extensively as photocatalysts for overall water splitting, but polymer photocatalysts are also receiving growing attention. So far, most studies involving organic polymers report hydrogen production with sacrificial electron donors, which is unsuitable for large-scale hydrogen energy production. Here we show that a linear conjugated polymer photocatalyst can be used for overall water splitting to produce stoichiometric amounts of $\mathrm{H}_{2}$ and $\mathrm{O}_{2}$. We studied a range of different metal co-catalysts in conjunction with the linear polymer photocatalyst, the homopolymer of dibenzo[ $[b, d]$ thiophene sulfone (P10). Photocatalytic activity was observed for palladium/iridium oxide-loaded P10, while other co-catalysts resulted in materials that showed no activity for overall water splitting. The reaction conditions were further optimized and the overall water splitting using the $\mathrm{IrO}_{2}$-loaded $\mathrm{P} 10$ was found to proceed steadily for an extended period (>60 hours) after the system stabilized. These results demonstrate that conjugated polymers can act as single component photocatalytic systems for overall water splitting when loaded with suitable co-catalysts, albeit currently with low activities. Significantly, though, organic polymers can be designed to absorb a large fraction of the visible spectrum, which can be challenging with inorganic catalysts. Transient spectroscopy shows that the $\mathrm{IrO}_{2}$ co-catalyst plays an important role in the generation of the charge separated state required for water splitting, with evidence for fast hole transfer to the co-catalyst. This solid-state approach should be transferable to other polymer photocatalysts, allowing this field to move away from sacrificial hydrogen production towards overall water splitting.
\end{abstract}




\section{Introduction}

Photocatalytic water splitting using semiconductor photocatalysts has been studied extensively for the past few decades. ${ }^{1-6}$ Photoelectrochemical ${ }^{3,6,7}$ and direct photocatalysis ${ }^{1-9}$ using particulate catalyst suspensions both have been explored. In principle, overall water splitting using photocatalyst suspensions is the simplest approach in technological terms, providing that the two gases can be separated economically. Photochemical systems could be amenable to large-scale deployment, potentially to a level that is competitive with fossil-fuel-derived hydrogen. ${ }^{2,8}$

Most particulate semiconductor photocatalysts reported to date are inorganic materials, ${ }^{1-15}$ but one well known challenge is to design materials that function in the visible part of the spectrum, as well as the UV. In the last decade, organic materials have shown promise due to their tunability (e.g., in terms of light absorption), and their potential to be produced inexpensively on large scale. ${ }^{12,13}$ Although organic photocatalysts were investigated widely after the first report of carbon nitride in $2009,{ }^{16}$ most studies have been confined to sacrificial half-reactions that produce either hydrogen or oxygen, not both. ${ }^{17-21}$ Few organic photocatalysts have been reported for overall water splitting. Carbon nitride materials have been coupled with metal oxides to facilitate overall water splitting in so called Z-schemes, whereby hydrogen evolution occurs on the organic photocatalyst while oxygen evolution occurs on the metal oxide. Both photocatalysts are excited and charges are transferred between the catalysts using redox mediators. ${ }^{22-}$ ${ }^{25}$ Similarly, we reported a Z-scheme for overall water splitting using a homopolymer of dibenzo[ $\left.b, d\right]$ thiophene sulfone (P10) as the hydrogen evolution catalyst, coupled with $\mathrm{BiVO}_{4}$ acting as the oxygen evolution catalyst using a $\mathrm{Fe}^{2+} / \mathrm{Fe}^{3+}$ redox mediator system. ${ }^{26}$ Overall water splitting occurred, but the solar efficiency was very low.

The use of redox mediators in Z-schemes can result in limitations arising from the kinetics of diffusion to and from the surface of the photocatalysts, surface interactions, and charge transfer between the mediator and the photocatalyst. The redox mediator can also result in potential sacrificial light absorption and the kinetics of both half reactions can be difficult to balance to facilitate overall water splitting with high efficiencies. Systems that use conductive layers are an alternative, but these also come with challenges in their fabrication. ${ }^{27}$

Single particulate polymer photocatalysts for overall water-splitting that do not rely on redox mediators could overcome these limitations but they are rare. Two 1,3,5-diyne-linked conjugated microporous polymers were claimed to act as single component organic photocatalysts for overall water splitting ${ }^{28}$ without any metal co-catalysts. Most reported systems require a metal co-catalyst to archive overall water splitting. ${ }^{27,29,30}$ This is because metal co-catalysts facilitate charge separation, ${ }^{31}$ store charges, and serve as reaction sites that catalyze water oxidation and reduction. ${ }^{24,32,33}$ As such, much effort has been spent in the development of co-catalysts for photocatalysis. ${ }^{34,35}$ For example, carbon nitride loaded with $\mathrm{Pt} / \mathrm{CoO}_{x}$ as co-catalyst was reported to be active for photocatalytic overall water splitting. ${ }^{36}$ Similarly, a covalent triazine-based framework loaded with $\mathrm{NiP}_{\mathrm{x}} / \mathrm{Pt}$ was reported to act as a single component photocatalyst for overall water splitting. ${ }^{37}$ Here, we explored the homopolymer of dibenzo[ $[b, d]$ thiophene sulfone (P10, Fig. 1a), which was shown previously to drive both proton reduction ${ }^{38}$ and water oxidation ${ }^{39}$ as separate half-reactions in the presence of appropriate sacrificial electron donors or acceptors. The linear conjugated polymer P10 is also predicted to be able to drive overall water splitting (Fig. 1b). Given the importance of co-catalysts, we explored a range of metals loaded onto P10 for overall water splitting in absence of sacrificial reagents. Overall water splitting reaction was found to proceed by using P10 loaded with iridium (P10-Ir) under optimized reaction conditions, which is the first example of single component photocatalyst for water splitting that uses a linear conjugated polymer. We then used transient spectroscopy to study the kinetics of the system and found that the co-catalyst opens up new kinetic pathways for the system. 


\section{Results and Discussion}

a)

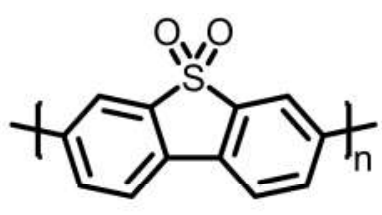

b)

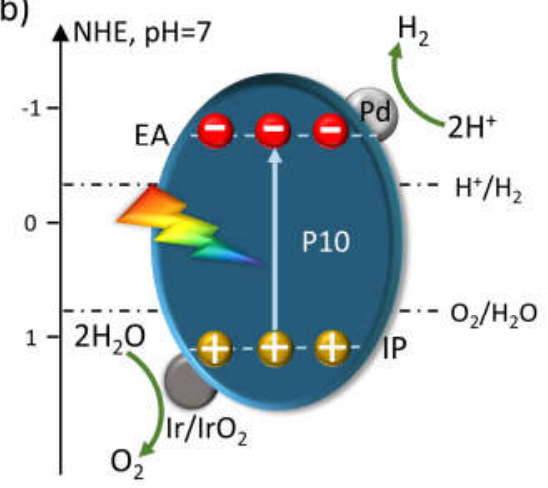

Figure 1. a) Chemical structure of the linear conjugated polymer photocatalyst P10; b) Alignment of the P10 energy levels (IP, ionization potential; EA, electron affinity) predicted by DFT relative to the potentials for proton reduction and water oxidation at $\mathrm{pH} 7$. Underlying data taken from ref. ${ }^{38}$

The photocatalyst P10 (the homopolymer of dibenzo[b, d]thiophene sulfone) was synthesized by $\operatorname{Pd}(0)$ catalyzed Suzuki-Miyaura cross-coupling reaction and purified using Soxhlet extraction with chloroform. Characterization was found to match our previous reports of the material. ${ }^{31,38} \mathrm{P} 10$ contains residual metallic palladium particles that act as a co-catalyst for hydrogen production, as we have shown previously. ${ }^{31}$ The literature suggests that a second co-catalyst would be required to facilitate simultaneous water oxidation, thus allowing for photocatalytic overall water splitting to take place. P10 was therefore further optimized by loading it with different co-catalyst using a microwave heating method. ${ }^{40}$ The activity of photocatalyst P10 loaded with various co-catalysts for overall water splitting is shown in Fig. 2a. Cobalt was found to enable water oxidation with $\mathrm{P} 10$ in the presence of silver(I) nitrate acting as an electron scavenger, ${ }^{39}$ but $\mathrm{P} 10$ loaded with $\mathrm{CoO}_{x}$ was found to be inactive for overall water splitting. Ruthenium oxide has also been reported as a efficiency hydrogen evolution co-catalyst, ${ }^{11,41}$ but it did not facilitate overall water splitting here, with only a small amount of hydrogen being produced without apparent oxygen production. By contrast, $\mathrm{IrO}_{2}$ loaded $\mathrm{P} 10$, formed by addition of $\mathrm{P} 10$ to an $\left[\mathrm{NH}_{4} \mid \mathrm{rCl} \mathrm{l}_{6}\right]$ aqueous solution prior to microwave heating and after irradiation in water, was found to be effective; overall water splitting proceeded under visible irradiation with initial rates of $5.6 \mu \mathrm{mol} \mathrm{h}^{-1}$ and $1.8 \mu \mathrm{mol} \mathrm{h}^{-1}$ for hydrogen and oxygen production under an experimental condition as shown in the caption of Figure 2. $\mathrm{P} 10-\mathrm{IrO}_{2}$ was also tested for sacrificial oxygen evolution using aqueous $\mathrm{AgNO}_{3}$ solution as the scavenger. Under these conditions, it was found that the photocatalyst produces oxygen (Fig. S-37), unlike P10 without iridium loading ${ }^{39}$ demonstrating the importance of the iridium in driving the water oxidation half reaction.

High-resolution transmission electron microscopy showed that metal particles were evenly distributed throughout the polymer and identified to be iridium and palladium by energy-dispersive X-ray spectroscopy (EDX) mapping (Fig. S-11). In line with previous reports, we observed palladium particles sized between 10 and $15 \mathrm{~nm}^{26,42}$ while the iridium particles were approximately $2 \mathrm{~nm}$ in diameter. During photocatalysis iridium is converted to $\mathrm{IrO}_{2}$ as evident from XPS measurements (Fig. 3a). It appears that the larger palladium particles are partially covered with $\mathrm{IrO}_{2}$, while also free small $\mathrm{IrO}_{2}$ particles exist. Palladium is very likely acting as the proton reduction catalyst, but it is also well-known to act as an electronhole recombination center in photocatalytic water splitting. ${ }^{43,44}$ 
a)

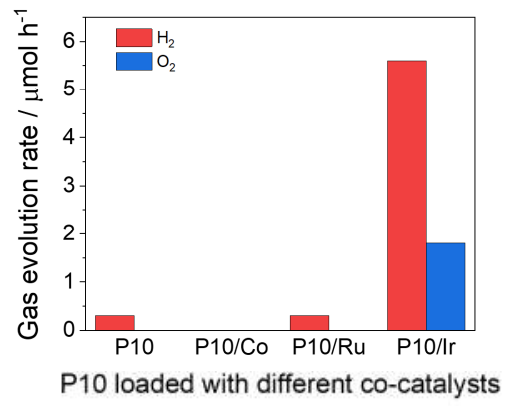

b)

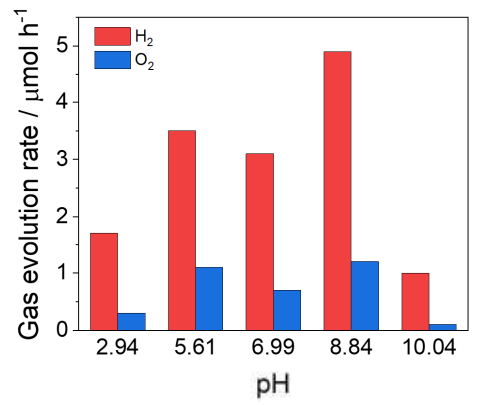

c)

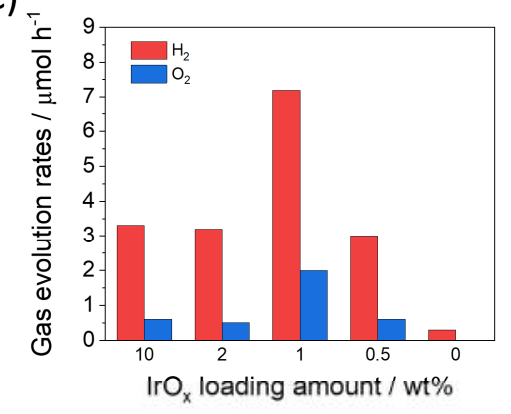

d)

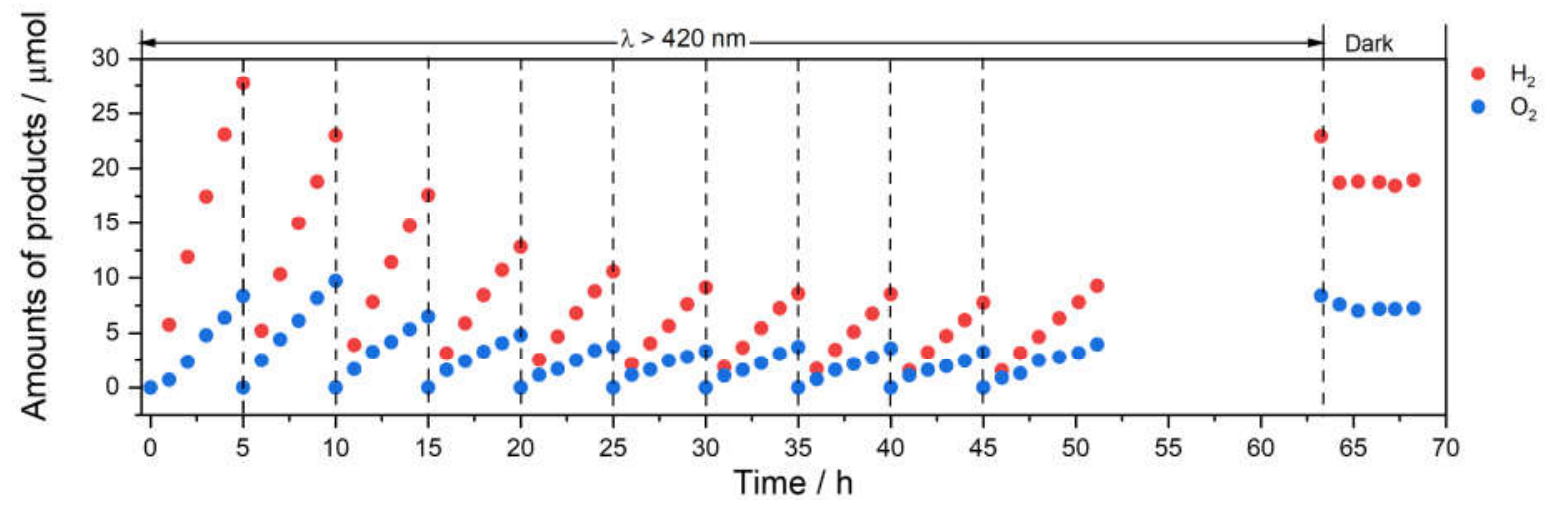

Figure 2. a) Dependence of gas evolution rates on the different co-catalyst (1 wt. \%) loaded onto P10 (1 mg) under visible light illumination; b) Effect of $\mathrm{pH}$ of reactant solution on photocatalytic water splitting over $\mathrm{P} 10-\mathrm{Ir}(1 \mathrm{mg})$ under visible light $(\lambda>420 \mathrm{~nm})$, pH was adjusted using $\mathrm{H}_{2} \mathrm{SO}_{4}$ or $\mathrm{KOH}$; c) Effect of loading amount of Ir cocatalyst on P10-Ir on photocatalytic water splitting under visible light $(\lambda>420 \mathrm{~nm})$; d) Photocatalytic water splitting over P10-Ir (1 mg) under visible light $(\lambda>420 \mathrm{~nm})$, the change of gas amount at 63 hours occurred because the reactor temperature changes after the light source was turned off. When left in the dark after the extended run the change in temperature results in an initial reduction of the measured gas products, but no further reduction of the amounts of $\mathrm{H}_{2}$ and $\mathrm{O}_{2}$ was observed, suggesting that no significant backward reaction was taking place. Experiments in a-d were carried out with PerkinEImer CERMAX PE300BF $300 \mathrm{~W}$ Xe light source with cut-off filters, irradiation area: $33 \mathrm{~cm}^{2}, \lambda>420 \mathrm{~nm}$; top-irradiation cell with a Pyrex window in a gas-closed circulation system. Reactant solution: distilled water $(120 \mathrm{~mL})$. Activities were calculated from photocatalytic experiments without initial stabilization over 5 hours $(\mathrm{a}-\mathrm{c})$.

The photocatalytic activity of $\mathrm{P} 10-\mathrm{Ir}$ was studied as a function of $\mathrm{pH}$ and was found to vary little in the $\mathrm{pH}$ range of $5.6-9.0$. Activities were lower at $\mathrm{pH} 2.9$ and $\mathrm{pH} 10$ (Fig. 2b). One possible explanation is the calculated ionisation potential and electron affinity of the polymer relative to the potential of water reduction and oxidation (S-39). At low $\mathrm{pH}$, the driving force (i.e., the difference between the water oxidation potential and the ionisation potential of the polymer) is small compared to higher $\mathrm{pH}$, while at the other extreme ( $\mathrm{pH} \mathrm{10),} \mathrm{the} \mathrm{difference} \mathrm{between} \mathrm{the} \mathrm{proton} \mathrm{reduction} \mathrm{potential} \mathrm{and} \mathrm{the} \mathrm{electron} \mathrm{affinity} \mathrm{of} \mathrm{the}$ polymer is smaller compared to that at lower $\mathrm{pH}$. It appears, therefore, that $\mathrm{pH}$ values close to $\mathrm{pH} 7$ offer sufficient driving force for both half reactions and therefore the highest photocatalytic activities. The water splitting activity of $\mathrm{P} 10-\mathrm{IrO}_{2}$ was not increased by using larger amounts of $\mathrm{P} 10-\mathrm{IrO}_{2}$ in water with the hydrogen evolution rate of $50 \mathrm{mg} \mathrm{P} 10-\mathrm{IrO}_{2}$ only slightly increasing to $10.9 \mu \mathrm{mol} \mathrm{h}^{-1}$ compared to experiments using $1 \mathrm{mg} \mathrm{P} 10-\mathrm{IrO}_{2}\left(5.6 \mu \mathrm{mol} \mathrm{h}^{-1}\right)$ as shown in Table 1. More significantly, there was no measured increase in the amount of oxygen produced, suggesting that the increase in hydrogen originated from either decomposition of impurities or auto-oxidation of the photocatalyst. 
Table 1. Photocatalytic water splitting under visible light illumination $(\lambda>420 \mathrm{~nm})$ for particulate conjugated polymer P10 in water.

\begin{tabular}{c|c|c|ccc}
\hline Entry & $\begin{array}{c}\text { Amount of P10 } \\
(\mathrm{mg})\end{array}$ & $\begin{array}{c}\text { Co-catalyst } \\
(\text { wt. \%) }\end{array}$ & $\begin{array}{c}\mathrm{H}_{2} \text { Evolution } \\
\text { rate } \\
\left.(\mu \mathrm{mol} \mathrm{h})^{-1}\right)^{\mathrm{b}}\end{array}$ & $\begin{array}{c}\mathrm{O}_{2} \text { Evolution rate } \\
(\mu \mathrm{mol} \mathrm{h})^{\mathrm{b}}\end{array}$ & $\begin{array}{c}\text { Kinetic } \\
\text { data }\end{array}$ \\
\hline 1 & 50 & $\operatorname{Ir}(0.45)$ & 10.9 & 0.7 & Fig. S-23 \\
2 & 10 & $\operatorname{Ir}(0.45)$ & 7.4 & 1.4 & Fig. S-24 \\
3 & 5 & $\operatorname{Ir}(0.45)$ & 6.6 & 2.1 & Fig. S-25 \\
4 & 3 & $\operatorname{Ir}(0.45)$ & 6.4 & 2 & Fig. S-26 \\
5 & 1 & $\operatorname{Ir}(0.45)$ & 5.6 & 1.8 & Fig. 2d \\
6 & 1 & $\operatorname{Co}(0.04)$ & 0 & 0 & - \\
7 & 1 & $\operatorname{Ru}(0.8)$ & 0.3 & 0 & Fig. S-35 \\
8 & 5 & $-c$ & 0.3 & 0 & Fig. S-36 \\
9 & 1 & $\operatorname{Ir}(0.45)$ & $2.1^{\mathrm{d}}$ & $0.9^{\mathrm{d}}$ & Fig. 2d \\
\hline
\end{tabular}

a Reaction conditions: P10 loaded with Ir, Co or Ru loaded by microwave deposition (details in ESI); 300 W Xe light source with a cut-off filter $(\lambda>420 \mathrm{~nm})$; cell, top-irradiation, 70 torr, Ar, reactant solution: distilled water; ${ }^{b}$ Gas evolution rates were calculated from the first run of the photocatalytic experiments; ${ }^{c}$ No additional co-catalyst was added; ${ }^{\mathrm{A}}$ After 20 hours equilibration.

We also tried to optimize the amount of Ir loaded onto P10 as shown in Fig. 2c. In the absence of iridium no photocatalytic overall water splitting is observed, and only a small amount of hydrogen is detected, which we have observed previously and can potentially be ascribed to the decomposition of impurities or auto-oxidation of the photocatalyst (Fig. S-36). ${ }^{18,38} \mathrm{~A}$ loading of $1 \%$ Ir on P10 gave the highest activity for water splitting with higher loadings $(2 \%$ and $10 \%)$ reducing the activity, possibly due to parasitic light absorption of the metal that competes with the polymer photocatalyst.

The initial photocatalytic evolution production rate of $5.6 \mu \mathrm{mol} \mathrm{h}^{-1}$ for hydrogen and $1.8 \mu \mathrm{mol} \mathrm{h}^{-1}$ for oxygen for $\mathrm{P} 10-\mathrm{IrO}_{2}$ (1\% Ir loading, $1 \mathrm{mg}, 120 \mathrm{~mL}$ water, $300 \mathrm{~W}$ Xe light source, $\lambda>420 \mathrm{~nm}$ ) decreased over each of the subsequent 5-hour runs before stabilising to constant water splitting at rates of $2.1 \mu \mathrm{mol} \mathrm{h}^{-1}$ for hydrogen and $0.9 \mu \mathrm{mol} \mathrm{h} \mathrm{h}^{-1}$ for oxygen production. The $\mathrm{H}_{2} / \mathrm{O}_{2}$ production ratio is close to 2 , within an experimental error after the stabilization period (Fig. 2d). Similar observations of a stabilisation period have been made previously for germanium nitride loaded with $\mathrm{RuO}_{2}$ nanoparticles. ${ }^{45}$ This might be caused by the oxidation of the iridium in $\mathrm{P} 10-\mathrm{Ir}$ to $\mathrm{IrO}_{2}$ (Fig. 3a) as evident from XPS measurements showing that metallic iridium is converted into $\mathrm{IrO}_{2}$ during light irradiation (Fig. 3a) - or by oxidation of residual compounds such as ethylene glycol used for the Ir-loading step as might indicated by the increased hydrogen evolution and reduced oxygen evolution. Detachment of the Ir species from the surface of $\mathrm{P} 10-\mathrm{IrO}_{2}$ during the early stages of the catalysis could also be a possible reason since the content of Ir in $\mathrm{P} 10-\mathrm{IrO}_{2}$ (1\% Ir loading) was reduced from $0.45 \%$ to $0.35 \%$ after the experiment (Table S-1). 
a)

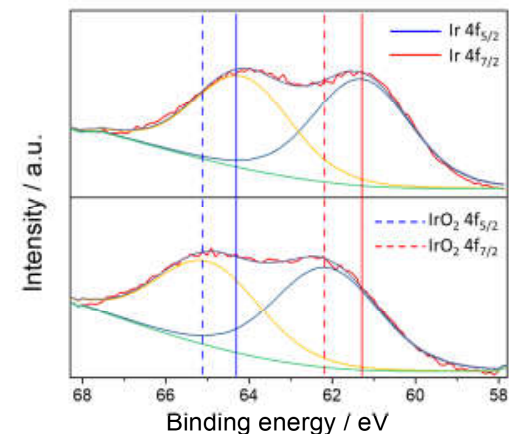

d)

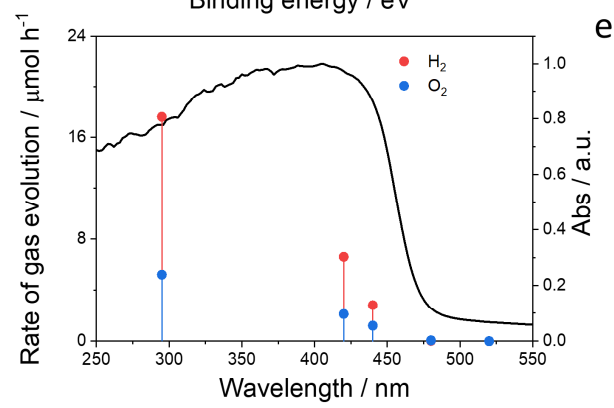

b)

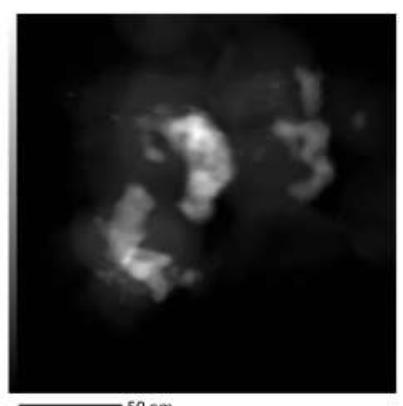

e)

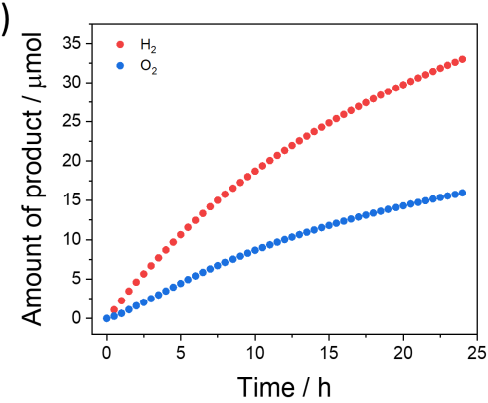

c)

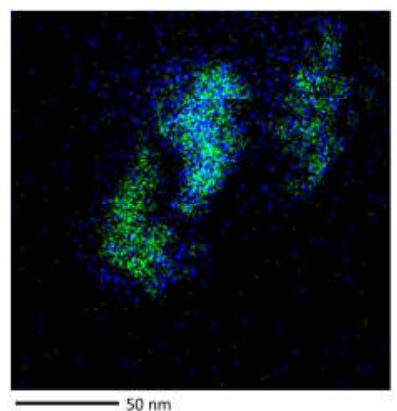

f)

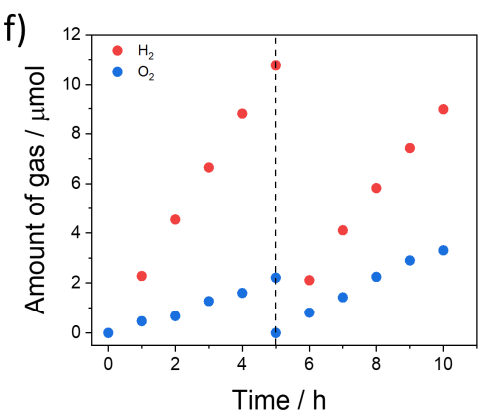

Figure 3. X-Ray photoelectron spectra of a) P10-Ir (top) and P10-IrO 2 (bottom); b) STEM-HAADF image of the photocatalyst after photocatalysis (the scale bar is $50 \mathrm{~nm}$ long); c) EDX mapping of the same area as in b showing the presence of palladium (green) and iridium (blue) (the scale bar is $50 \mathrm{~nm}$ long). d) Wavelength dependence of photocatalytic water splitting over P10-Ir $(1 \mathrm{mg})$ in distilled water $(120 \mathrm{~mL})$ in gas-closed circulation system, light source: $300 \mathrm{~W}$ Xe-arc light source with different cut-off filters, irradiation area: $33 \mathrm{~cm}^{2}$; e) Photocatalytic water splitting over P10-Ir (1 mg) in distilled water $(120 \mathrm{~mL})$ in Ar-flow system (1 atm) under visible light $(\lambda>420 \mathrm{~nm}, 300$ W, irradiation area: $\left.33 \mathrm{~cm}^{2}\right)$; f) Photocatalytic solar water splitting over P10-Ir (1 mg) in distilled water (120 mL) in gas-closed circulation system, light source: solar simulator with an AM1.5G filter (100 mW cm-2$)$, irradiation area: $25 \mathrm{~cm}^{2}$.

The total amount of hydrogen evolved was $148.7 \mu$ mol over 63 hours, which was larger than the amount of hydrogen in P10-Ir sample $(14 \mu \mathrm{mol})$. The turnover number was determined to be 54.1 after 63 hours per mole of repeat unit of $\mathrm{P} 10$ based on a 4-hole hole transfer to water resulting in oxygen production (see ESI for calculations, Eq. S-3). Post illumination analysis also showed no significant changes in the UV-vis, photoluminescence, FT-IR spectra, and PXRD patterns for the catalysts (Fig. S-1 to S-4). These results clearly demonstrated that P10-Ir is a photocatalyst suitable for overall water splitting even when other reports indicate that sustained water oxidation is difficult to maintain for organic materials. ${ }^{39,46}$

P10-Ir showed higher rates of $17.6 \mu \mathrm{mol} \mathrm{h}^{-1}$ and $5.2 \mu \mathrm{mol} \mathrm{h}^{-1}$ for $\mathrm{H}_{2}$ and $\mathrm{O}_{2}$ production under broadband illumination (full arc, $300 \mathrm{~W}$ Xe light source, 70 torr) when compared to visible $(\lambda>420 \mathrm{~nm}$ ) light alone $\left(\mathrm{H}_{2}: 5.6 \mu \mathrm{mol} \mathrm{h}^{-1}\right.$ and $\left.\mathrm{O}_{2}: 1.8 \mu \mathrm{mol} \mathrm{h}^{-1}\right)$. This is expected as the photocatalyst $\mathrm{P} 10$ absorbs both UV and visible photons (Fig. 3d). The rates of hydrogen and oxygen evolution are reduced to $2.8 \mu \mathrm{mol} \mathrm{h}^{-1}$ and $1.2 \mu \mathrm{mol} \mathrm{h}{ }^{-1}$ with a $440 \mathrm{~nm}$ long-pass cut-off filter, only $0.03 \mu \mathrm{mol} \mathrm{h}{ }^{-1}$ and $0.06 \mu \mathrm{mol} \mathrm{h}^{-1}$ with a $480 \mathrm{~nm}$ filter, and no photocatalytic activity was observed when using a $520 \mathrm{~nm}$ cut-off filter $(300 \mathrm{~W}$, Xe light source; 70 torr). This shows that the efficiency tracks the absorption profile of $\mathrm{P} 10-\mathrm{IrO}_{2}$ and that process is driven by the absorption of light.

The experiments described above were performed under reduced pressure, which allows for both hydrogen and oxygen gas to be driven off the surface. To test the activity of P10-Ir under atmospheric pressure experiments were performed in a flow system with an argon carrier gas (flow rate = $\left.15 \mathrm{~mL} \mathrm{~min}{ }^{-1}\right)$. These experiments demonstrated that under visible irradiation $(\lambda>420 \mathrm{~nm}) \mathrm{P}^{10}-\mathrm{IrO}_{2}$ also 
produces $\mathrm{H}_{2}$ and $\mathrm{O}_{2}$ from water at ambient pressure (Fig. 3e) with lower but measurable rates $\left(\mathrm{H}_{2}\right.$ : $1.36 \mu \mathrm{mol} \mathrm{h}^{-1}, \mathrm{O}_{2}: 0.66 \mu \mathrm{mol} \mathrm{h}^{-1}$ ) in a 2.06:1 ratio.

Under a solar simulator, we observed rates of $1.8 \mu \mathrm{mol} \mathrm{h}^{-1}$ for $\mathrm{H}_{2}$, and $0.7 \mu \mathrm{mol} \mathrm{h}{ }^{-1}$ for $\mathrm{O}_{2}$ after 5 hours stabilization (Fig. 3f). Finally, again using a solar simulator, the solar-to-hydrogen efficiency (STH) was determined to be $0.0047 \%$ (Eq. S-6). This is a more than 3-times improvement compared to our previous report of $\mathrm{P} 10$ in a Z-scheme with $\mathrm{BiVO}_{4}(0.0014 \%) .{ }^{26}$ The low STH efficiency can be explained, in part, by the low polymer loading: much of the light passes through the reactor without being absorbed. Inorganic photocatalysts, such as aluminum-doped strontium titanate loaded with $\mathrm{Rh} / \mathrm{Cr}_{2} \mathrm{O}_{3} / \mathrm{CoOOH}$ have shown much higher STH values of $0.65 \% .{ }^{12}$ However, we note that the catalytic activity for sacrificial hydrogen evolution in organic polymers increased by a factor of 600 in the period 2015 (pyrene networks) ${ }^{17}$ to 2020 (bulk heterojunction materials) ${ }^{47,48}$ and thus far, only a very small number of polymer photocatalysts have been reported for overall water splitting.

Transient absorption (TA) UV/vis spectroscopy can provide evidence of the mechanism of photocatalysis and was used previously to study the formation and fate of the P10 electron polaron during hydrogen ${ }^{31,38}$ and oxygen ${ }^{39}$ evolution, as well as in a Z-scheme device ${ }^{26}$. Excitation at $400 \mathrm{~nm}$ of $\mathrm{P} 10$ and $\mathrm{P} 10-\mathrm{IrO}_{2}$ (post-photocatalysis) in water under an Ar atmosphere leads to similar spectra on the ps-ns timescales, Figure 4. The broad positive absorption peaking at ca. $870 \mathrm{~nm}$ has been assigned elsewhere to excited -state absorption by a singlet exciton state, ${ }^{38}$ which we show below is actually composed of spectral features of 2 or more states. These excitonic states can radiatively decay back to the ground state, with stimulated emission giving rise to the negative features, with the spectral position coinciding with the broad band observed in the steady-state emission spectra of $\mathrm{P} 10$ and $\mathrm{P} 10-\mathrm{IrO}_{2}$ suspensions (Figure S18). Alternatively, a long-lived polaronic state can be formed that has an absorption maximum at $637 \mathrm{~nm}$ (P10) or $635 \mathrm{~nm}\left(\mathrm{P} 10-\mathrm{IrO}_{2}\right)$. The assignment of this TA band to a polaronic state is based on past experiments where in the presence of a sacrificial electron donor a P10 electron polaron was found to persist for hundreds of microseconds prior to electron transfer to the Pd HER catalyst. ${ }^{31}$ In the absence of a sacrificial electron donor, similar spectral features are typically assigned to a polaron pair. ${ }^{38}$ The presence of $\mathrm{IrO}_{2}$ accelerates the decay of the broad positive absorption assigned to the P10 excitonic states (Figure $4 \mathrm{c}, \mathrm{d})$, with the difference clearly noticeable at times < 2 ps. In contrast the rate of recovery of the negative bleach assigned to stimulated emission shows no clear dependence on $\mathrm{IrO}_{2}$ on the ps-ns timescale (Figure $4 \mathrm{e}, \mathrm{f}$ ). Therefore, either an additional non-radiative decay pathway becomes available, or an acceleration of an existing pathway occurs, when $\mathrm{IrO}_{2}$ is present in $\mathrm{P} 10$. 

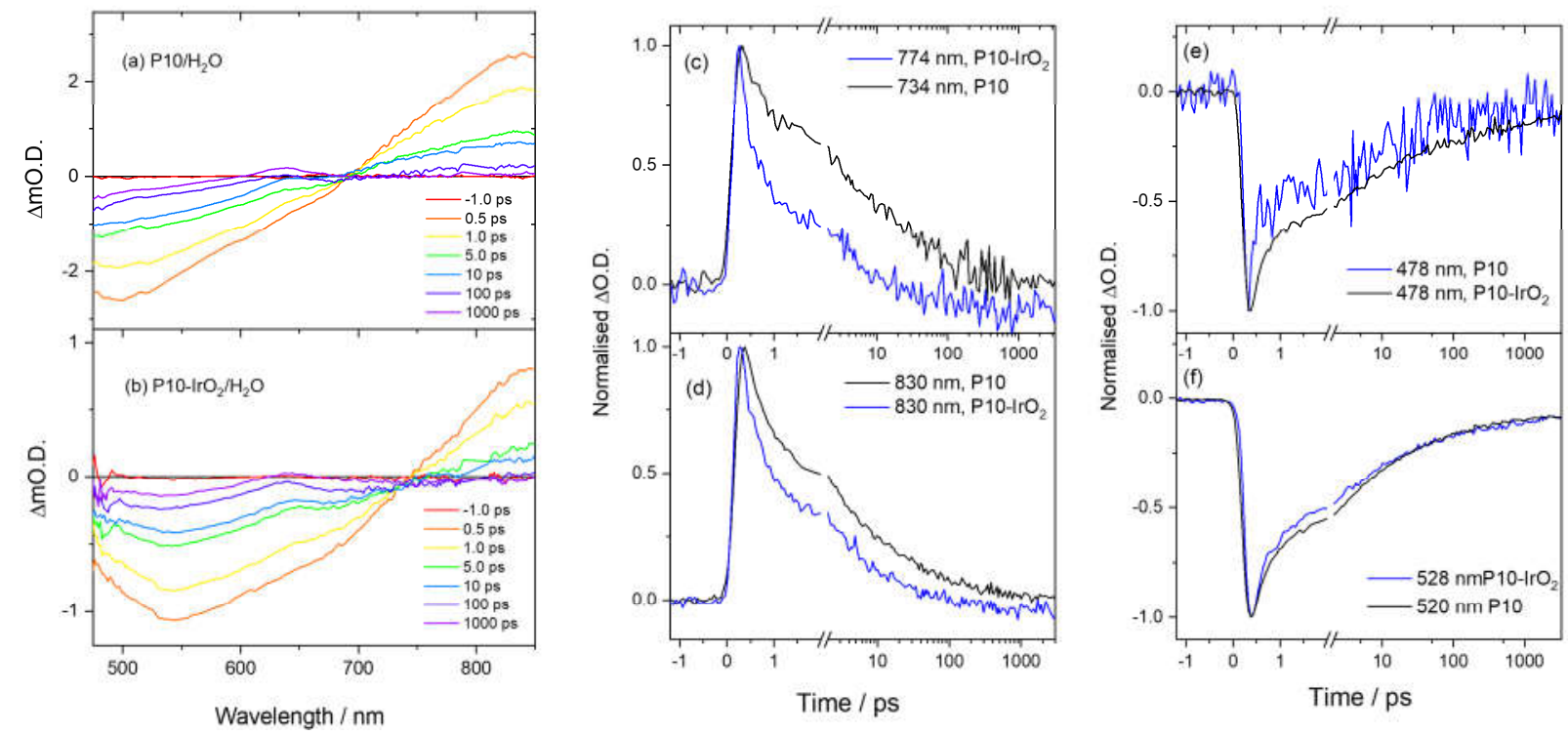

Figure 4. a) TA difference spectra of $\mathrm{P} 10$ and b) $\mathrm{P} 10-\mathrm{IrO}_{2}$ (post photocatalysis) in water following $400 \mathrm{~nm}$ excitation. c) and d) kinetic traces showing the decay of the photoinduced absorption of P10 and P10-Ir $\mathrm{O}_{2}$ at wavelengths that the global fitting identified as maxima in the species associated spectra. e) and f) kinetics of the stimulated emission of P10 and P10- $\mathrm{IrO}_{2}$.

To identify this pathway and to obtain the spectral fingerprints of individual components from the complex overlapping spectra, global target analysis was carried out on both data sets. Full details of the procedure and the global lifetime approach, which requires fewer assumptions but still provides similar conclusions, are given in the Supporting Information. The kinetic model consists of three states, an initially generated excited state $(0)$ which can populate two lower energy states $(1,2)$. Initial fitting with a 2-compartment mode consisting solely of an initially generated excitonic state and a charge separated state gave a poor fit to the experimental data. Based on the global lifetime analysis, we allowed transfer of population from compartment 0 to 1 and 2, and from 1 to 2 . In addition, all 3 compartments were allowed to relax to the ground state (Figure $5 a, b$ ). The lifetimes and relative yield of each kinetic pathway are shown in Figure 5 a,b,e. 
(a)

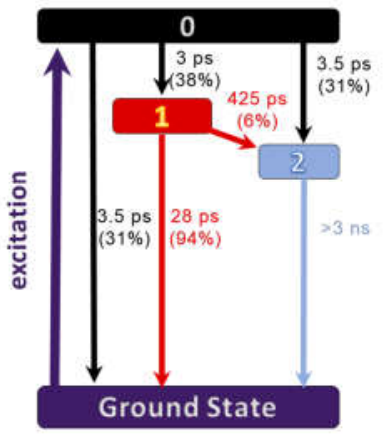

(b)

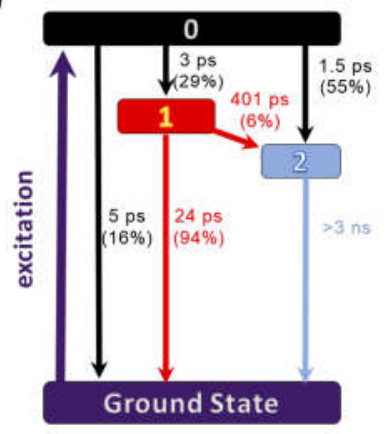

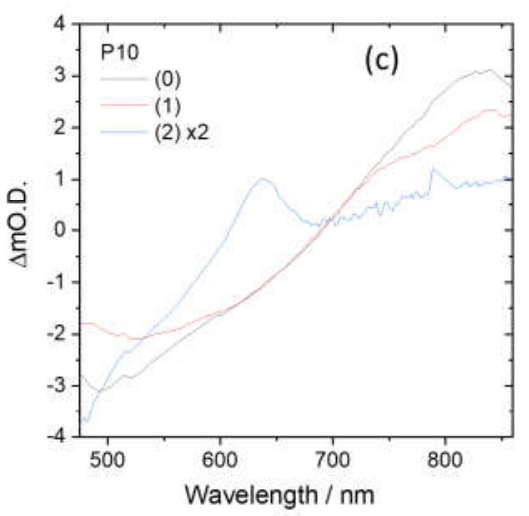
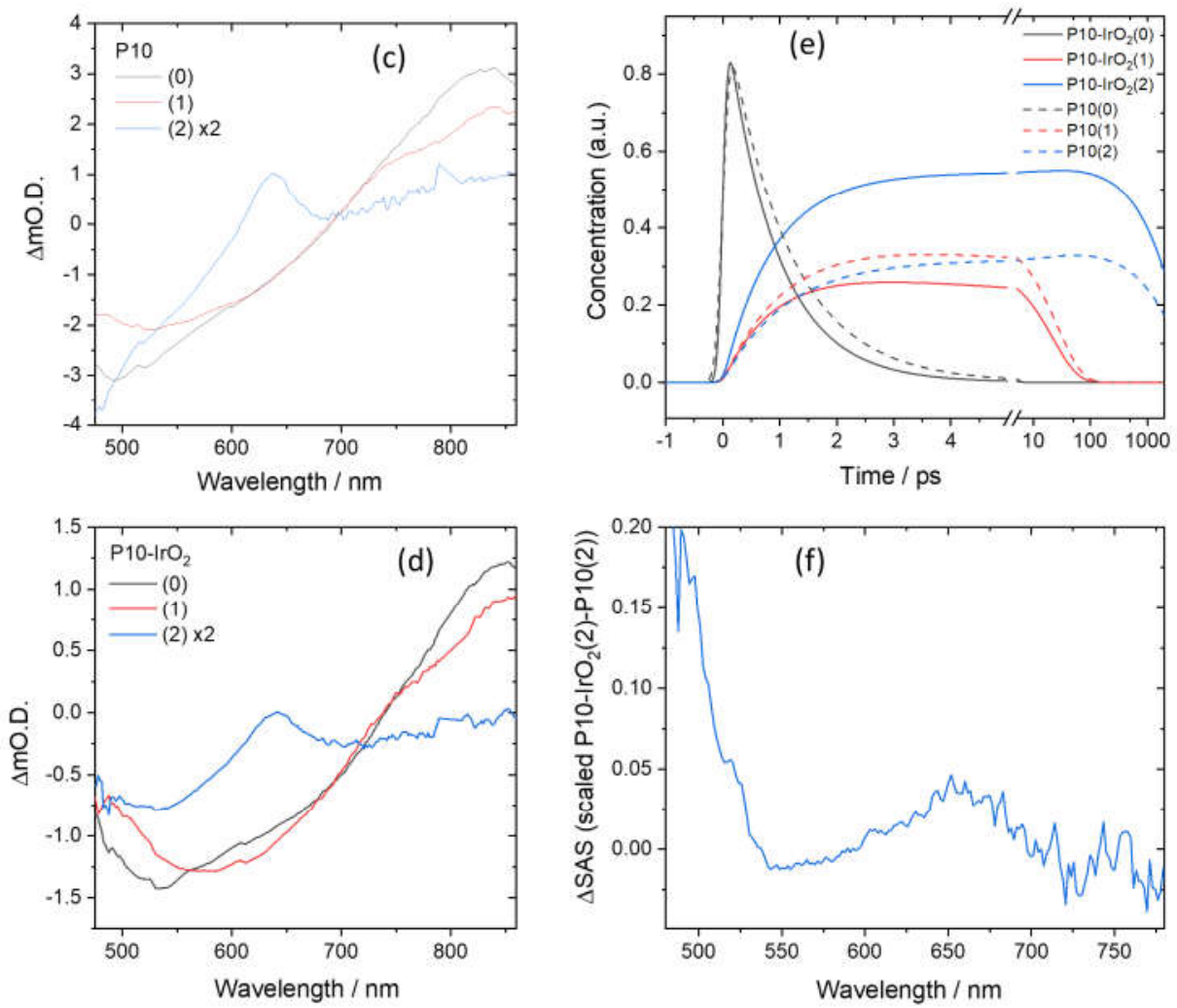

Figure 5. a) Kinetic model used for the global target analysis of the TA spectra of $\mathrm{P} 10$ and b) $\mathrm{P} 10-\mathrm{IrO}_{2}$ following $400 \mathrm{~nm}$ excitation which shows accelerated formation of the P10 polaron species (2) in the presence of the $\mathrm{IrO}_{2}$ which is the charge separated state involved in photocatalysis. c) SAS of components $0,1,2$ generated for $\mathrm{P} 10$ and d) $\mathrm{P} 10-\mathrm{IrO}_{2}$. e) Calculated amplitudes of the individual species with time. The dashed lines represent P10 and the solid lines P10-IrO ${ }_{2}$ f) Difference in SAS of component 2 of $\mathrm{P} 10-\mathrm{IrO}_{2}$ and $\mathrm{P} 10$ indicating hole transfer to the $\mathrm{IrO}_{2}$ co-catalyst. The relative intensity of the spectra

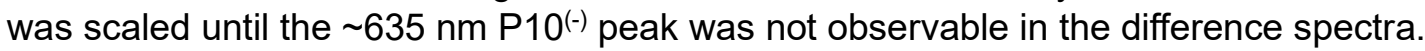

The species associated spectra (SAS) generated in the global fitting procedure for $\mathrm{P} 10$ and $\mathrm{P} 10-\mathrm{IrO}_{2}$ are shown in Figure $5 \mathrm{c}, \mathrm{d}$. Species 0 and 1 both have characteristic features of the singlet excitonic state. Given this observation, along with the identical time that species 1 takes to form in the presence and absence of $\mathrm{IrO}_{2}$, it can be assigned to a singlet excitonic state, which likely forms following vibrational relaxation of the initially formed hot state (species 0 ). The SAS of species 2 (P10) has a maximum at ca. $635 \mathrm{~nm}$ which agrees with the previously reported polaron pair and electron polaron spectra of P10. Interestingly the $\mathrm{P} 10-\mathrm{IrO}_{2}$ SAS of species 2 shows a broadening of the $635 \mathrm{~nm}$ peak and an increasing $\triangle$ O.D. below $550 \mathrm{~nm}$ when compared to the P10 SAS of species 2 . Subtracting the SAS of the polaronic states of $\mathrm{P} 10$ from $\mathrm{P} 10-\mathrm{IrO}_{2}$ gives rise to the spectrum shown in Figure $5 \mathrm{f}$. The difference in the SAS spectra of $\mathrm{P} 10$ and $\mathrm{P} 10-\mathrm{Ir}$ is proposed to be due to rapid hole transfer to the $\mathrm{IrO}_{2}$ giving rise to a charge separated $\mathrm{P} 10^{(-)}-\mathrm{IrO}_{2}{ }^{(+)}$state (2), which goes on to enables water oxidation at the $\mathrm{IrO}_{2}$ catalyst and hydrogen evolution via electron transfer to the $\mathrm{Pd}$ co-catalyst. We note a good agreement between the feature present in Figure $4 a$ and the UV/vis spectrum reported of oxidized $\mathrm{IrO}_{2}$ obtained through spectroelectrochemistry, supporting this assignment. ${ }^{49}$ Our modelling of the TA data indicates the primary pathway for formation of the polaronic states of both $\mathrm{P} 10$ and $\mathrm{P} 10-\mathrm{IrO}_{2}$ is directly from the initially generated hot exciton state (0). Relaxation into the lower energy excitonic state (1) represents a loss pathway with it primarily decaying to the ground state (94\%). The yield and rate of formation of the polaron (2) is 
greater with the $\mathrm{P} 10-\mathrm{IrO}_{2}$ sample (Figure $5 \mathrm{e}$ ), which rationalizes the decreased lifetime of the photoinduced absorption at $\lambda>700 \mathrm{~nm}$ (Figure $5 \mathrm{c}, \mathrm{d}$ ). It is striking that the lifetime of formation of $\mathrm{P} 10^{(-)}-\mathrm{IrO}_{2}{ }^{(+)}$is estimated to be only $1.5 \mathrm{ps}$ allowing it to compete with the kinetics of recombination, which enables water oxidation using a single polymer photocatalyst.

Besides P10, a number of other linear conjugated polymers are known experimentally to drive both proton reduction and water oxidation in the presence of sacrificial donors ${ }^{39}$ and many more should theoretically be able to drive overall water splitting based on their predicted ionization potential and electron affinity. ${ }^{20}$ The results presented here for $\mathrm{P} 10$ suggest that many of these polymers might be active for overall water splitting in the presence of suitable co-catalysts and that such polymer photocatalysts can be relatively stable for this reaction under the right operating conditions.

\section{Conclusions}

In summary, iridium-loaded on $\mathrm{P} 10$ was found to be a co-catalyst for the decomposition of $\mathrm{H}_{2} \mathrm{O}$ into $\mathrm{H}_{2}$ and $\mathrm{O}_{2}$, representing the first successful example of an organic photocatalyst for overall water splitting based on a linear conjugated polymer. Overall water splitting of P10 loaded with $\mathrm{IrO}_{2}$ co-catalyst proceeded steadily for an extended period of time (>60 hours). The photocatalytic activity was strong dependent on the co-catalysts with only Ir co-catalyst found to drive overall water splitting for the P10 photocatalyst. Transient absorption UV/vis spectroscopy was used to study the photocatalytic system and species associated spectra analyzed were generated. The analysis suggest that a charge separated $\mathrm{P} 10(-)-\mathrm{IrO}_{2}\left(^{+}\right)$state is formed rapidly that enables water oxidation at the $\mathrm{IrO}_{2}$ catalyst and hydrogen evolution via electron transfer to the $\mathrm{Pd}$ co-catalyst, highlighting the importance of the Ir-cocatalyst. Although the overall solar-to-hydrogen efficiency of this first system is very low with respect to inorganic semiconductors, as for the first embodiments of polymers for sacrificial hydrogen production, ${ }^{17}$ it provides proofof-concept study that linear polymer photocatalysts can in principle move away from using sacrificial reagents for hydrogen production. ${ }^{50}$

\section{Methods}

Synthesis of the polymer photocatalyst: P10 was synthesized as previous report. P10 was co-loaded with $\mathrm{IrO}_{2}$ as oxidation cocatalyst. $0.2 \mathrm{~g} \mathrm{P} 10$ was dispersed in ethylene glycol ( $40 \mathrm{~mL}$ ) followed by the addition of an appropriate amount of an $\left[\mathrm{NH}_{4} \mathrm{IrCl}_{6}\right]$ aqueous solution $\left(2 \mathrm{wt}\right.$. $\% \mathrm{IrO}_{2}$, calculated based on elemental Ir). The mixture was transferred into a glass vial and heated in a microwave reactor (Monowave 300 , Anton Paar Company) at $423 \mathrm{~K}$ for 30 minutes.

Photocatalytic water splitting experiments: Water splitting experiments were carried out in gas-closed circulation and Ar-flow systems. The P10-Ir (0.05-0.001 g) photocatalyst powder was dispersed in distilled water $(120 \mathrm{~mL})$ in a reaction cell made of Pyrex glass. A top-irradiation cell with a Pyrex window was used after degassing by applying vacuum and purging with argon. The set-up was brought back to reduced pressure (70 torr) and irradiated with a $300 \mathrm{~W}$ Xe arc light source (PerkinEImer; CERMAX PE300BF) or a solar simulator (Yamashita Denso; YSS-80QA, $100 \mathrm{~mW} \mathrm{~cm}^{-2}$ ). The measurement of wavelength dependency was carried out using a $300 \mathrm{~W}$ Xe-arc light source with cut-off filters (HOYA). Amounts of evolved hydrogen and oxygen were determined using an online gas chromatograph (Shimadzu; GC-8A, MS-5Å column, TCD, Ar carrier).

Transient absorption spectroscopy experiments: Suspensions were prepared with $\mathrm{P} 10$ or $\mathrm{P} 10-\mathrm{IrO}_{2}$ (post photocatalysis, $0.35 \mathrm{wt}$ \% Ir loading) concentration of $0.24 \mathrm{~g} \mathrm{~L}^{-1}$ and ultrasonicated in water until the photocatalyst was dispersed (20 minutes). The suspension was transferred into a quartz cuvette with a $2 \mathrm{~mm}$ pathlength, sealed with a rubber septa cap and degassed by Ar bubbling for 20 minutes. Samples were not stirred during ultrafast TAS measurements as they were found to be suitably stable during the 
TA experiment (ca. 30 minutes). TA spectra were collected on a Harpia-TA spectrometer (Light Conversion). The pump light was generated using a Pharos-SP-10W (Light conversion, FWHM $170 \mathrm{fs}, 10 \mathrm{kHz}$, $1030 \mathrm{~nm}$ ) coupled to a OPA (Orpheus), an internal chopper lowers the pump frequency to $5 \mathrm{kHz}$. The white light probe beam was achieved by focusing a portion of the Pharos-SP-10W output on to a sapphire crystal within the Harpia spectrometer. Samples were excited with a $400 \mathrm{~nm}$ pump light with a power of $750 \mu \mathrm{W}$. The pump beam (ca. $0.6 \mathrm{~mm}$ diameter) and the probe beam (ca. $0.4 \mathrm{~mm}$ diameter) were overlapped on the sample position. Data was initially collected using the Harpia-TA spectrometer and analysed using Carpetview software (Light Conversion).

Data availability. All data generated and analysed relevant to the study are included in the article and the Supplementary Information files.

Supplemental Information includes: Figures S1-S41, Tables S1-S2, hydrogen and oxygen evolution setup and measurement data, UV-vis spectra, gas sorption data, FT-IR, X-ray powder diffraction, scanning electron microscope, transmission electron microscope, TON/STH calculation, time correlated single photon counting, transient absorptions spectra and global analysis of TA data.

\section{AUTHOR INFORMATION}

\section{Corresponding Authors}

sebastian.sprick@strath.ac.uk

aicooper@liverpool.ac.uk

a-kudo@rs.tus.ac.jp

acowan@liverpool.ac.uk

\section{Acknowledgments}

We thank the Engineering and Physical Sciences Research Council (EPSRC) for financial support under Grants EP/N004884/1 and EP/P034497/1. We acknowledge the University of Liverpool's Early Career Researcher Laser Laboratory, (EPSRC, EP/S017623/1) in which we performed TA measurements, operated by UoL Shared Research Facilities. Y.B. thanks the China Scholarship Council for a Ph.D. studentship The Great Britain Sasakawa Foundation (No. 5611) for financial support, and the Accelerated Materials Development for Manufacturing Program at A*STAR via the AME Programmatic Fund by the Agency for Science, Technology and Research under Grant no. A1898b0043. We also thank JSPS KAKENHI Grant Numbers $17 \mathrm{H} 06433$ in Scientific Research on Innovative Areas "Innovations for LightEnergy Conversion (I4LEC)" and 17H0127, and 20K15383 for financial support. R.S.S. thanks the University of Strathclyde for financial support through The Strathclyde Chancellor's Fellowship Scheme. Dr Q. Wang and Dr A. D. Handoko are acknowledged for useful discussions. 


\section{REFERENCES}

[1] A. Kudo, H. Kato, I. Tsuji, Chem. Lett. 2004, 33, 1534-1539.

[2] A. Kudo, Y. Miseki, Chem. Soc. Rev. 2009, 38, 253-278.

[3] R. Abe, J. Photochem. Photobiol. C Photochem. Rev. 2010, 11, 179-209.

[4] K. Maeda, J. Photochem. Photobiol. C Photochem. Rev. 2011, 12, 237-268.

[5] K. Maeda, ACS Catal. 2013, 3, 1486-1503.

[6] T. Hisatomi, J. Kubota, K. Domen, Chem. Soc. Rev. 2014, 43, 7520-7535.

[7] M. G. Walter, E. L. Warren, J. R. McKone, S. W. Boettcher, Q. Mi, E. A. Santori, N. S. Lewis, Chem. Rev. 2010, 110, 6446-6473.

[8] K. Maeda, K. Domen, Bull. Chem. Soc. Jpn. 2016, 89, 627-648.

[9] S. Chen, T. Takata, K. Domen, Nat. Rev. Mater. 2017, 2, 1-17.

[10] Y. Wang, H. Suzuki, J. Xie, O. Tomita, D. J. Martin, M. Higashi, D. Kong, R. Abe, J. Tang, Chem. Rev. 2018, 118, 5201-5241.

[11] Q. Wang, T. Hisatomi, Q. Jia, H. Tokudome, M. Zhong, C. Wang, Z. Pan, T. Takata, M. Nakabayashi, N. Shibata, Y. Li, I. D. Sharp, A. Kudo, T. Yamada, K. Domen, Nat. Mater. 2016, 15, 611615.

[12] Q. Wang, M. Nakabayashi, T. Hisatomi, S. Sun, S. Akiyama, Z. Wang, Z. Pan, X. Xiao, T. Watanabe, T. Yamada, N. Shibata, T. Takata, K. Domen, Nat. Mater. 2019, 18, 827-832.

[13] T. Takata, J. Jiang, Y. Sakata, M. Nakabayashi, N. Shibata, V. Nandal, K. Seki, T. Hisatomi, K. Domen, Nature 2020, 581, 411-414.

[14] K. Watanabe, A. Iwase, A. Kudo, Chem. Sci. 2020, 11, 2330-2334.

[15] H. Nishiyama, T. Yamada, M. Nakabayashi, Y. Maehara, M. Yamaguchi, Y. Kuromiya, H. Tokudome, S. Akiyama, T. Watanabe, R. Narushima, S. Okunaka, N. Shibata, T. Takata, T. Hisatomi, K. Domen, Nature 2021, 598, 304-307.

[16] X. Wang, K. Maeda, A. Thomas, K. Takanabe, G. Xin, J. M. Carlsson, K. Domen, M. Antonietti, Nat. Mater. 2009, 8, 76-80.

[17] R. S. Sprick, J. X. Jiang, B. Bonillo, S. Ren, T. Ratvijitvech, P. Guiglion, M. A. Zwijnenburg, D. J. Adams, A. I. Cooper, J. Am. Chem. Soc. 2015, 137, 3265-3270.

[18] R. S. Sprick, B. Bonillo, R. Clowes, P. Guiglion, N. J. Brownbill, B. J. Slater, F. Blanc, M. A. Zwijnenburg, D. J. Adams, A. I. Cooper, Angew. Chemie - Int. Ed. 2016, 55, 1792-1796.

[19] C. Yang, B. C. Ma, L. Zhang, S. Lin, S. Ghasimi, K. Landfester, K. A. I. Zhang, X. Wang, Angew. Chemie - Int. Ed. 2016, 55, 9202-9206.

[20] Y. Bai, L. Wilbraham, B. J. Slater, M. A. Zwijnenburg, R. S. Sprick, A. I. Cooper, J. Am. Chem. Soc. 2019, 141, 9063-9071.

[21] Y. Bai, D. J. Woods, L. Wilbraham, C. M. Aitchison, M. A. Zwijnenburg, R. S. Sprick, A. I. Cooper, J. Mater. Chem. A 2020, 8, 8700-8705. 
[22] D. J. Martin, P. J. T. Reardon, S. J. A. Moniz, J. Tang, J. Am. Chem. Soc. 2014, 136, 1256812571.

[23] G. Zhang, Z. A. Lan, L. Lin, S. Lin, X. Wang, Chem. Sci. 2016, 7, 3062-3066.

[24] Z. Pan, Y. Zheng, F. Guo, P. Niu, X. Wang, ChemSusChem 2017, 10, 87-90.

[25] Y. Lin, W. Su, X. Wang, X. Fu, X. Wang, Angew. Chemie - Int. Ed. 2020, 59, 20919-20923.

[26] Y. Bai, K. Nakagawa, A. J. Cowan, C. M. Aitchison, Y. Yamaguchi, M. A. Zwijnenburg, A. Kudo, R. S. Sprick, A. I. Cooper, J. Mater. Chem. A 2020, 8, 16283-16290.

[27] Q. Wang, K. Domen, Chem. Rev. 2020, 120, 919-985.

[28] L. Wang, Y. Wan, Y. Ding, S. Wu, Y. Zhang, X. Zhang, G. Zhang, Y. Xiong, X. Wu, J. Yang, H. $\mathrm{Xu}$, Adv. Mater. 2017, 29, 1702428.

[29] Y. Sasaki, A. Iwase, H. Kato, A. Kudo, J. Catal. 2008, 259, 133-137.

[30] Y. Bai, K. Hippalgaonkar, R. S. Sprick, J. Mater. Chem. A 2021, 9, 16222-16232.

[31] M. Sachs, H. Cha, J. Kosco, C. M. Aitchison, L. Francàs, S. Corby, C. L. Chiang, A. A. Wilson, R. Godin, A. Fahey-Williams, A. I. Cooper, R. S. Sprick, I. McCulloch, J. R. Durrant, J. Am. Chem. Soc. 2020, 142, 14574-14587.

[32] H. Song, X. Meng, S. Wang, W. Zhou, X. Wang, T. Kako, J. Ye, J. Am. Chem. Soc. 2019, 141, 20507-20515.

[33] Z. Zou, J. Ye, K. Sayama, H. Arakawa, Mater. Sustain. Energy A Collect. Peer-Reviewed Res. Rev. Artic. from Nat. Publ. Gr. 2010, 704, 293-296.

[34] B. H. Meekins, P. V. Kamat, J. Phys. Chem. Lett. 2011, 2, 2304-2310.

[35] R. Asai, H. Nemoto, Q. Jia, K. Saito, A. Iwase, A. Kudo, Chem. Commun. 2014, 50, 2543-2546.

[36] L. Lin, Z. Lin, J. Zhang, X. Cai, W. Lin, Z. Yu, X. Wang, Nat. Catal. 2020, 3, 649-655.

[37] S. Zhang, G. Cheng, L. Guo, N. Wang, B. Tan, S. Jin, Angew. Chemie 2020, 132, 6063-6070.

[38] M. Sachs, R. S. Sprick, D. Pearce, S. A. J. Hillman, A. Monti, A. A. Y. Guilbert, N. J. Brownbill, S. Dimitrov, X. Shi, F. Blanc, M. A. Zwijnenburg, J. Nelson, J. R. Durrant, A. I. Cooper, Nat. Commun. 2018, 9, 1-11.

[39] R. S. Sprick, Z. Chen, A. J. Cowan, Y. Bai, C. M. Aitchison, Y. Fang, M. A. Zwijnenburg, A. I. Cooper, X. Wang, Angew. Chemie 2020, 132, 18854-18859.

[40] G. Ma, S. Chen, Y. Kuang, S. Akiyama, T. Hisatomi, M. Nakabayashi, N. Shibata, M. Katayama, T. Minegishi, K. Domen, J. Phys. Chem. Lett. 2016, 7, 3892-3896.

[41] Y. Shen, Q. Zheng, H. Zhu, T. Tu, Adv. Mater. 2020, 32, 1-9.

[42] R. S. Sprick, Y. Bai, A. A. Y. Guilbert, M. Zbiri, C. M. Aitchison, L. Wilbraham, Y. Yan, D. J. Woods, M. A. Zwijnenburg, A. I. Cooper, Chem. Mater. 2019, 31, 305-313.

[43] T. Kanazawa, K. Maeda, ACS Appl. Mater. Interfaces 2016, 8, 7165-7172.

[44] K. Yamaguti, S. Sato, J. Chem. Soc. Faraday Trans. 1 Phys. Chem. Condens. Phases 1985, 81, 1237-1246. 
[45] J. Sato, N. Saito, Y. Yamada, K. Maeda, T. Takata, J. N. Kondo, M. Hara, H. Kobayashi, K. Domen, Y. Inoue, J. Am. Chem. Soc. 2005, 127, 4150-4151.

[46] H. H. Cho, L. Yao, J. H. Yum, Y. Liu, F. Boudoire, R. A. Wells, N. Guijarro, A. Sekar, K. Sivula, Nat. Catal. 2021, 4, 431-438.

[47] H. Yang, X. Li, R. S. Sprick, A. I. Cooper, Chem. Commun. 2020, 56, 6790-6793.

[48] J. Kosco, M. Bidwell, H. Cha, T. Martin, C. T. Howells, M. Sachs, D. H. Anjum, S. Gonzalez Lopez, L. Zou, A. Wadsworth, W. Zhang, L. Zhang, J. Tellam, R. Sougrat, F. Laquai, D. M. DeLongchamp, J. R. Durrant, I. McCulloch, Nat. Mater. 2020, 19, 559-565.

[49] H. Ooka, Y. Wang, A. Yamaguchi, M. Hatakeyama, S. Nakamura, K. Hashimoto, R. Nakamura, Phys. Chem. Chem. Phys. 2016, 18, 15199-15204.

[50] E. A. Gibson, Nat. Catal. 2021, 4, 740-741. 